\title{
FLEISCHER, Soraya Resende. Parteiras, buchudas e aperreios: uma etnografia do atendimento obstétrico não oficial em Melgaço, Pará
}

\section{Rodrigo Toniol}

\section{(2) OpenEdition}

Journals

Edição electrónica

URL: http://journals.openedition.org/aa/547

DOI: $10.4000 /$ aa. 547

ISSN: 2357-738X

Editora

Programa de Pós-Graduação em Antropologia Social (UnB)

\section{Edição impressa}

Data de publição: 31 dezembro 2013

Paginação: 271-275

ISSN: 0102-4302

\section{Refêrencia eletrónica}

Rodrigo Toniol, «FLEISCHER, Soraya Resende. Parteiras, buchudas e aperreios: uma etnografia do atendimento obstétrico não oficial em Melgaço, Pará », Anuário Antropológico [Online], v.38 n.2 | 2013 , posto online no dia 01 dezembro 2014, consultado o 28 abril 2021. URL: http:// journals.openedition.org/aa/547 ; DOI: https://doi.org/10.4000/aa.547

Este documento foi criado de forma automática no dia 28 abril 2021.

\section{(c) (1) $(9)$}

Anuário Antropológico is licensed under a Creative Commons Atribuição-Uso Não-Comercial-Proibição de realização de Obras Derivadas 4.0 International. 


\title{
FLEISCHER, Soraya Resende. Parteiras, buchudas e aperreios: uma etnografia do atendimento obstétrico não oficial em Melgaço, Pará
}

\author{
Rodrigo Toniol
}

\section{REFERÊNCIA}

FLEISCHER, Soraya Resende. 2011. Parteiras, buchudas e aperreios: uma etnografia do atendimento obstétrico não oficial em Melgaço, Pará. Belém: Paka-Tatu, Edunisc. 351 pp.

1 Têm repercutido com certa frequência na produção das Ciências Sociais na última década críticas a perspectivas que estendem os supostos limites dos domínios sociais aos efeitos de poder das práticas, dos objetos e dos fenômenos "neles" inscritos. Tratase de desconfiar das consequências reificantes de recomendações como "para falar de religião, vá até os religiosos". Se uma das consequências teóricas de tais críticas tem sido o questionamento das fronteiras disciplinares, dos invólucros e dos campos sociais, do ponto de vista metodológico elas também têm contribuído para deslocar a atenção dos pesquisadores daquilo que é "propriamente" religioso, saúde, ciência etc. para as fronteiras, os interstícios e as práticas implicadas nos contextos observados.

2 Parteiras, Buchudas e Aperreios. Uma etnografia do cuidado obstétrico não oficial na cidade de Melgaço, Pará, de Soraya Fleischer, é um exemplo da incorporação deste tipo de problematização numa etnografia. Produzido originalmente como uma tese de doutorado, defendida em 2007 no Programa de Pós-Graduação em Antropologia Social da Universidade Federal do Rio Grande do Sul, o livro, lançado em 2011, é o resultado de um intenso trabalho de campo realizado no pequeno município de Melgaço, no arquipélago do Marajó, Pará. Trata-se de uma investigação sobre a prática de parteiras e 
seus encontros com o sistema de saúde nacional, com ONGs feministas, com o Estado e com o próprio partejar, as parturientes e suas redes de parentesco.

o livro chega em um momento bastante oportuno, quando políticas públicas têm se voltado para o reconhecimento de saberes e práticas tradicionais, tornando-as "oficiais". Embora a autora marque, já no título, que se ocupa do atendimento obstétrico não oficial, sua etnografia não se deixa apreender pelo conjunto de oposições a que o termo remete (oficial/ não oficial, popular/ hegemônico, tradicional/ biomédico). Diante desse contexto em que o que está em jogo é sobretudo a relação entre aquilo que provisoriamente é oficial e não oficial, a autora opta por um caminho alternativo ao daqueles pesquisadores que oscilam entre observar tais relações como sintomáticas de "mudanças de paradigma da biomedicina" e aqueles que reconhecem nela o poder da captura dos sistemas médicos que incorporam outros saberes, "neutralizando-os". A minúcia do trabalho etnográfico é o que permite a Soraya Fleischer complexificar as expectativas sobre o ofício das parteiras que "nem sempre desmedicalizam o parto, mas tampouco o patologizam ao extremo" (:18). É desse modo que as descrições em Parteiras, buchudas e aperreios evitam a todo custo a exotização daquelas mulheres do interior do Pará que, longe de encarnarem estereótipos projetados sobre elas, contribuem para situar melhor os limites das próprias políticas de saúde no Brasil, sobretudo aquelas pautadas pelos ideais da humanização.

O não oficial, enquanto termo qualificador do atendimento das parteiras de Melgaço, não significa, portanto, que essas mulheres não se encontrem o tempo todo com o Estado e sua "oficialidade" - aliás, esta designação, que descreve pela negação, é fruto desses encontros. Eles se dão, contudo, também pela existência e a mediação feita por uma série de atores sociais e instituições, como é o caso de ONGs dedicadas a articular parteiras de todo o país, oferecer cursos de formação, promover eventos dedicados a conferir legitimidade ao ofício etc. Foi por meio de uma dessas organizações - que muitas vezes alternam entre exaltar a eficiência de uma prática milenar e sublinhar sua primitividade, seu caráter "natural" porque mais próximo da "natureza" - que a própria antropóloga chegou até as mulheres de Melgaço. Restringir o trabalho de campo a espaços como ONGs, eventos ou reuniões de comitês municipais, no entanto, faria com que Soraya Fleischer apenas "tateasse o verniz que as parteiras caprichavam em exibir nessas aparições públicas que lhes eram oportunizadas pela classe médica militante, pela mídia e por instituições governamentais" (:21-22). Com isso, opta pelo cotidiano das parteiras em seu próprio contexto de trabalho, o que também insere um tema central para o livro: o interesse pelas práticas das parteiras.

5 Estar atenta às práticas, isto é, aos usos, aos fazeres, às ações (e também aos discursos) é apresentado pela autora a partir de seu diálogo com Sherry Ortner (1999). Contudo, o uso do termo ao longo do livro volta-se para modelos de problematização que extrapolam a teoria da prática de Ortner. Assim, destaco como questões transversais aos capítulos três conjuntos de problematizações relacionadas com a ideia de prática: a transmissão de conhecimento, os procedimentos e o estilo de fazer.

6 A partir do conceito de authoritative knowledge, da antropóloga Brigitte Jordan (1997), Soraya Fleischer converte questões mais substancialistas do tipo Como se faz uma parteira? em questões sobre relações de poder em que a legitimidade e a autoridade tornam-se temas incontornáveis. O conceito, que apresenta o "conhecimento" como "um estado que é atingido colaborativamente dentro de uma comunidade de práticas" (:34), permite-nos redimensionar o estatuto "local" das práticas das parteiras de 
Melgaço, inserindo tais práticas em uma comunidade mais ampla, de modo a sublinhar que a legitimidade das parteiras se funda tanto nas hierarquias e nas rivalidades locais, como também no modo como cada uma delas está articulada com ONGs de fora, com a Política Nacional de Parteiras Tradicionais e com políticas estaduais. A prática, neste caso, é o que permite falar do local sem circunscrevê-lo a localismos. Assim, a transmissão de conhecimento torna-se um modo de problematização na medida em que ela remete ao authoritative knowledge e ao conjunto de relações de poder em que estas mulheres estão envolvidas.

7 Um segundo conjunto de questões relacionado ao interesse pela prática diz respeito aos procedimentos das parteiras. Ainda que as referências teóricas que orientam a maior parte das reflexões presentes no texto sejam tributárias de perspectivas em que o corpo é tomado como um executor de conhecimentos estruturados, as descrições sobre o partejar, as massagens, a puxação, os remédios caseiros e a manipulação das plantas para aliviar as dores são minuciosas. Chamar a atenção para os diversos tipos de procedimentos também é, nesse caso, uma tentativa de dar visibilidade àquilo que, embora apareça no texto como resultado de estruturas estruturadas, pode ser lido na chave de perspectivas mais afeitas à fenomenologia, tal como o paradigma da corporeidade, de Thomas Csordas (2008), e as ideias de Tim Ingold (2010) sobre conhecimento.

8 Por fim, um último conjunto de questões também associadas à atenção da autora às práticas das parteiras refere-se ao estilo de fazer, sintetizado, aqui, como popular. 0 popular constitui-se no texto a partir de sua oposição ao institucional, oficial e disciplinar, convertendo-se numa espécie de qualificador das práticas das parteiras. Se, por um lado, marcar a diferença entre o popular e o oficial permite ao leitor perceber as descontinuidades entre as práticas dos sujeitos implicados em cada um desses estilos de fazer, por outro, este tipo de perspectiva também contribui para invisibilizar possíveis continuidades entre elas. Concebe-se a diversidade das práticas, mas elas são encerradas em estilos que as transcendem, informando-as (ou aprisionando-as).

Embora o trabalho de campo realizado por Soraya Fleischer tenha se estendido a diversos espaços pelos quais as parteiras transitavam, em Melgaço a antropóloga optou por seguir somente uma parteira. Esta opção metodológica não tornou sua etnografia uma biografia, tampouco a autora tenta convencer o leitor de que Dona Dorca - a parteira que Soraya Fleischer acompanhou - é um caso emblemático ou representativo da "média" das outras parteiras da cidade. Mas é através de Dona Dorca que conhecemos Melgaço, as práticas do partejar, as outras parteiras e, ainda, que pensamos sobre antropologia.

No primeiro capítulo do livro, o leitor é apresentado a Melgaço e aos percursos percorridos pela autora até sua recepção na cada de Dona Dorca. No capítulo seguinte, o foco torna-se a puxação. Curiosamente, é a partir deste tipo de massagem abdominal feita durante o ciclo reprodutivo que a autora situa o partejar não oficial para além do parto - e até mesmo da gestação. É durante a puxação que as mulheres falam sobre suas vidas, sobre seus relacionamentos. Também é pelo pagamento da puxação que somos inseridos na dimensão do dilema das parteiras sobre quanto custam seus serviços. Quem é cobrado? Quando se cobra? Quanto vale um parto? Estas questões, abordadas no terceiro capítulo, não somente inserem novas dimensões no partejar, como também explicitam que nem todos os partos são iguais, para cobrar e para cuidar. No quarto capítulo, Soraya Fleischer dedica-se justamente às diferenças entre os partos, fáceis e difíceis, na casa e no hospital. É neste capítulo que reconhecemos com maior precisão 
os momentos em que as parteiras decidem acionar a oficialidade, outros cuidadores e diferentes fontes de authoritative knowledge. Por fim, no último capítulo, passamos das diferenças entre os partos para as diferenças entre as parteiras, que se situam em sistemas de valorização do ofício a partir de seus contatos com ONGs, partos difíceis, cursos etc.

11 Com uma etnografia que se adensa conforme a leitura avança, Parteiras, buchudas $e$ aperreios é um texto refinado que insere problematizações fundamentais sobre o não oficial nos debates atuais das políticas de saúde. Em certo sentido, o livro não é nem sobre parteiras, nem sobre buchudas, e tampouco sobre aperreios, mas sobre o modo pelo qual esses sujeitos e essas sensações são centrais para se compreender, de modo mais amplo, saúde e reprodução fora de certos marcos tanto oficiais, biomédicos, como também interpretativos.

\section{BIBLIOGRAFIA}

CSORDAS, Thomas. 2008. Corpo/ significado/ cura. Porto Alegre: Editora da UFRGS.

FLEISCHER, Soraya. 2006. "Bolsas, livros, camisetas e certificados: ou o que as parteiras de Melgaço têm a dizer sobre os cursos de treinamentos". Seminário Internacional Fazendo Gênero 7, Florianópolis.

INGOLD, Tim. 2010. "Da transmissão de representações à educação da atenção". Educação, Porto Alegre, 33(1):6-25.

JORDAN, Brigitte. 1997. “Authoritative knowledge and its construction”. In: Robbie Davis-Floyd \& Carolyn F. Sargent (orgs.). Chilbirth and authoritative knowledge: Cross-cultural perspectives. Berkeley: Univesity of California Press. pp. 55-79.

ORTNER, Sherry. 1999. "Introduction". In: Sherry Ortner (org.). The fate of "culture": Geertz and beyond. Berkeley: University of California Press. pp.1-13.

\section{AUTORES}

RODRIGO TONIOL

PPGAS/UFRGS 